\section{AUTOR}

José Jobson de

Andrade Arruda*

jobson.a@uol.com.br

* Profesor senior de

Departamento de Historia

de la Universidade de São

Paulo

\title{
Imperios coloniales del Atlántico Sur e iberismo
}

\author{
Impérios coloniais do Atlântico Sul e iberismo
}

Colonial Empires in the South Atlantic and Iberism

RESUMEN

El presente artículo tiene un perfil teórico, historiográfico e histórico. Discute la pertinencia de las interpretaciones que se pueden identificar como pertenecientes a la moderna teoría de los imperios coloniales ibéricos, cuestionando las proposiciones deconstructivistas que estuvieron presentes en las formulaciones de los imperios negociados, polisinodiales, a los cuales se opone la noción de sistema colonial y capitalismo comercial apuntando hacia la originalidad de las arquitecturas políticas de los Estados y su importancia en la configuración del iberismo.

\section{RESUMO}

O presente artigo tem um perfil teórico, historiográfico e histórico. Discute a pertinência das interpretações que podem ser identificadas como pertencentes à moderna teoria dos impérios coloniais ibéricos, questionando as proposições desconstrutivistas que estiveram presentes nas formulações dos impérios negociados, polissinoidais, aos quais se opõe a noção de sistema colonial e capitalismo comercial, apontando para a originalidade das arquiteturas políticas dos Estados e sua importância na configuração do iberismo.

\section{ABSTRACT}

This paper addresses the subject from a theoretical, historiographical and historical point of view. We discuss the appropriateness of interpretations that might be identified as concerning the modern theory of Iberian Colonial Empires. We question the deconstructivist proposals present in the formulations of negotiated, poly-synodal Empires, which are opposed to the notion of colonial system and mercantile capitalism, highlighting the originality of the political architecture of States and its importance in the shaping of Iberism. 
El abordaje de la categoría "Imperio" presupone la distinción entre la historiografía entendida en su primera acepción, o sea, el arte de producir obras históricas, y la historiografía en su dimensión más refinada, que es el análisis crítico de las obras de historia producidas por los historiadores y de los propios historiadores en su inmersión histórico-cultural. Significa pensar las obras históricas por aquello que son capaces de expresar, es decir, el entorno problematizado de las múltiples temporalidades que en ella se entrecruzan, exponiendo el tiempo a partir del cual hablan de sus autores, así como los universos sociales, la ambientación cultural y las motivaciones políticoideológico-institucionales de sus constructores'. En la imposibilidad de, en este momento, realizar la intrincada tarea que esta segunda acepción exige, enfocaremos la cuestión en su fórmula simplificada, esto es, asumiendo el abordaje historiográfico en su sentido común.

Son extremadamente variados las nociones, categorías y conceptos movilizados por la comunidad de expertos en el afán de encuadrar la realidad histórica múltiple correspondiente a los tres siglos que median entre los descubrimientos marítimos y la era de las revoluciones. Entre ellas, la categoría Imperio ganó un espacio amplio en el rol de las interpretaciones que rastrean la especificidad y el movimiento temporal de las experiencias históricas que demarcaron el papel desempeñado por las monarquías europeas en el mundo americano y afroasiático durante ese período. A la luz de las categorías más elásticas y comprensivas de Edad Moderna y Antiguo Régimen, la categoría Imperio pierde en especificidad y densidad histórica ante los conceptos de colonia y capitalismo comercial, especialmente cuando enfocamos la experiencia histórica singular del Imperio portugués, involucrando la neurálgica relación metrópolis-colonia en el espacio crucial del Atlántico Sur. Por otro lado, la categoría Imperio y, específicamente, el análisis de los procesos históricos que fueron contemporáneos de los imperios coloniales ibéricos comenzaron a tener una gran visibilidad en función de su implicación en la formulación de la moderna teoría política del iberismo.

La jerarquización conceptual, en lo que respecta a su capacidad explicativa, está sujeta a la segmentación temática prevista. Depende de la realidad histórica que se pretenda reconstruir. Podemos decir que, en la perspectiva de la dimensión económico-social, por ejemplo, la categoría Imperio es genérica, una categoría abierta, al contrario del concepto de colonia, que encierra un sentido específico; generalidad que se refleja en la multiplicidad de acepciones que el término puede entrañar, como se verá a continuación.

\section{Imperios negociados (Jack P. Greene) e imperios coalescentes (Mark Greengrass)}

La teoría de los imperios negociados, concepción opuesta a la de los imperios absolutamente dueños de sus acciones e instrumentos de gobierno, nace en sus primeras formulaciones de los estudios de Jack P. Greene que enfocan la relación entre el centro y la periferia en los años ochenta ${ }^{2}$, tesis ampliamente influenciada por las concepciones del sociólogo Edward Shils-vehiculadas en los años sesenta sobre la relación centro-periferia como una construcción sociocultural ${ }^{3}$ - para quien, dada la flaqueza del poder coercitivo de las sociedades premodernas, las estructuras sociales y políticas en las áreas periféricas obtenían considerable grado de autonomía.

Fue exactamente la capacidad de coacción, o de resistencia, la que se convirtió en la piedra angular de los análisis de Jack P. Greene, tomada de Shils, pero que él expandió de formas variables y creativas, enfatizando el dominio ejercido por los colonos sobre las estructuras locales de poder que, a pesar de que hubieran sido implantadas por el poder central metropolitano, se erigieron a partir de los esfuerzos de los colonos en formas de edificación política local fundadas al estilo 
europeo en el nuevo mundo. Así, la autoridad central no se ejercía de arriba hacia abajo, sino a través de un elaborado proceso de negociación en el cual la autoridad tenía implicaciones en la legitimidad, la justicia y el derecho ${ }^{4}$. En estos términos, los imperios coloniales modernos eran "monarquías compuestas en las cuales el mando era indirecto, la soberanía fragmentada, el gobierno consensual y considerable la autoridad que se dejaba para la periferia"

Más allá de la inspiración shildiana, en mucho contribuyeron a la consolidación de esta vertiente interpretativa de los imperios coloniales, basada en la experiencia histórica de las trece colonias, los análisis producidos por Mark Greengrass sobre los estados modernos europeos ${ }^{6}$.

En contraposición con las interpretaciones que sobrevaloraban el papel dominante de los estados modernos centralizados, el historiador considera la estructuraeuropea."dominada porunamultiplicidad de entidades políticas regionales", robustas y duraderas, un mosaico complejo de entidades que se contaban por centenares en 1500, una rica variedad de tradiciones políticas que incluían "vastos y antiguos estados estabilizados, nuevos principados, imperios dinásticos, ciudades-estado, confederaciones" y una concepción idealizada de la monarquía universal consustanciada en el Sacro Imperio Romano-Germánico y en la jurisdicción temporal y espiritual del papado ${ }^{7}$.

La idea de los estados coalescentes, estados fusionados, amalgama de procesos longevos de aglutinación, agregaciones más o menos heterogéneas, se desarrolló en la escritura greeneana para la concepción de las autoridades negociadas y llegó a su extremo en la formulación de imperios negociados en el texto de Christine Daniels, análisis combinados que acabaron por constituir una teoría de la naturaleza de los imperios en la época moderna con afán de generalización, pero que se basaba empíricamente en la experiencia histórica particular de la monarquía inglesa y sus colonias americanas y caribeñas.

\section{Imperios compuestos: John Elliott}

Estados coalescentes e imperios negociados se reproducen en las monarquías y en los "imperios compuestos", conforme a la denominación formulada por John Elliot, en su texto sobre del Imperio español en América ${ }^{8}$, obra de síntesis cuyas raíces se encuentran en el artículo publicado en 1992 en relación con las monarquías compuestas en Europa ${ }^{9}$. Centrado en la experiencia histórica española durante el proceso de formación del Estado ibérico liderado por la monarquía, el autor habla de los arreglos negociados, incluso en casos de conquista, que implicaron un elevado grado de continuidad de los gobiernos locales, capaces de retener una parcela considerable del mando local en sus manos. Como dice Elliot, un sistema de monarquías compuestas, en las cuales las partes constituyentes precedieron a la propia fusión, preservando, por esta vía, "diferentes leyes, derechos, privilegios y tradiciones"10.

El imperio compuesto es fruto de la monarquía compuesta, experimentada en Europa antes de ser ejecutada en los dominios coloniales americanos. Si así fuera, el Imperio español se iba a sustentar más en la cooptación que en la coerción. Elites locales, así como estratos sociales inferiores, podrían expresar sus opiniones y hacerse oír. El sistema fiscal, estructura neurálgica en el espacio imperial, era resultado de negociaciones complejas, involucrando los intereses metropolitanos, la administración colonial, los súbditos, las corporaciones y los individuos. Las cajas, sistema hacendístico regional, estaban sometidas a los intereses de las elites locales, a las que incumbía la distribución dela rentagenerada porel imperioentre las diferentes regiones, entre las diferentes cajas, en un sistema cooperativo entre las elites regionales y locales, implementando las transferencias de recursos como empresarios privados, mecanismo a través del cual se apropiaban de parte de la renta generada por el sistema, garantizando al mismo tiempo fluidez financiera y adhesión social al sistema económico, cuyo árbitro supremo era el monarca español.

El mecanismo de las transferencias intercoloniales garantizaba los recursos indispensables para el aprovisionamiento del aparato administrativo y militar sin que el poder central tuviera necesidad de recurrir a la coerción, con la ventaja suplementaria de promover la integración del mercado interno colonial con la financiación de las relaciones entre 
mercados urbanos y rurales. En consecuencia, la Corona prescindió de la maximización de la extracción de excedentes vía exacción fiscal, aunque eso significara una recaudación inferior de recursos, disminuyendo las tensiones y garantizando la longevidad del imperio, un procedimiento que funcionaba como si estuviera garantizado por una constitución no escrita. En estos términos, el Imperio español en América se caracterizaría por ser: no absolutista, no centralizado, no depredador, no extractor de rentas; una exacerbación del esquema interpretativo de John Elliot, que surge en algunos de sus seguidores más fervientes ${ }^{11}$.

Si el monarca español actuaba como árbitro supremo en el ámbito del Imperio y de él nada aprovechaba, seria cuestionable cuáles serían las bases materiales de su sustento, de dónde vendrían los recursos económico-financieros que alimentaban a la monarquía española, el cotidiano dispendioso de la realeza, el aparato burocrático, los cuerpos militares, la armada, las plazas de guerra, las campañas militares, el ocio de la nobleza, las edificaciones religiosas y el modo de vida del clero, si nada se transfería para la metrópoli. ¿No había extracción directa de la riqueza metálica en la forma de plata y oro de las minas americanas? ¿Y los monopolios comerciales o los rendimientos derivados del tráfico de esclavos realizado por los asentistas?

Aun reconociendo que pueda haber pesado en exceso en las interpretaciones que priorizan las relaciones de dominio y subordinación entre metrópolis y colonias, que el Estado monárquico español pudiera tener, de hecho, un carácter compuesto, la transferencia de este arquetipo interpretativo a la esfera colonial genera problemas de difícil solución, como aquellos anteriormente referidos. Más compleja aún sería la transferencia de este patrón interpretativo para la esfera del Imperio portugués, pues ni la monarquía tuvo la misma oblicuidad coalescente en su formación, ni el espacio de su actuación en América presentaba las mismas características de la América española, marcada por la preexistencia de imperios, civilizaciones, culturas y experiencias históricas de alta densidad. Esto no quiere decir que los portugueses operaran en un territorio vacío, sino que las condiciones de resistencia y, por tanto, la necesidad de acomodación con las poblaciones instaladas secularmente en el territorio, fueron muy distintas.

\section{Imperios polisinodiales: António Manuel Hespanha}

A pesar de esas evidencias históricas indiscutibles, el esquema interpretativo que venía presentándose para los imperios erigidos por ingleses y españoles repercutió sobre la comunidad de historiadores portugueses, especialmente sobre el distinguido historiador del derecho António Manuel Hespanha, responsable de la fórmula emblemática del imperio polisinodial $^{12}$.

En su perspectiva, la inexistencia de un poder centralizado en los dominios controlados por los portugueses en los tres continentes, yespecialmente en las partes americanas, se expresaría en varios niveles: en la falta de un proyecto colonizador; en la ausencia de una constitución colonial unificada; en el pluralismo del derecho colonial; en la precedencia de las normas y de las costumbres locales sobre las leyes más generales, prevaleciendo el derecho narrativo; en la autonomía de la justicia criolla (sic) que generaba una plétora de derechos no oficiales; en la apropiación del poder por las autoridades gubernamentales en ejercicio en la colonia, asumiendo los tribunales locales prerrogativas reales; en la solidaridad entre las autoridades y las elites locales. Así se caracteriza la "colonización" de la administración del Imperio portugués ${ }^{13}$.

Hespanha exige al sistema de colonización portugués y a la propia práctica colonizadora lo que ella no podría ofrecer: un sistema formal y legal maduro, sea de las directrices generales de la política metropolitana para la colonia, sea de la posibilidad de aclimatación de un sistema jurídico moderno al espacio colonial, responsabilizándolo por la prevalencia de las prácticas locales que redundaron en la colonización de la estructura administrativa del imperio, constataciones que, incluso siendo verdaderas, no invalidan el carácter centralizado de la monarquía en su territorio o del imperio en los espacios coloniales. Solamente le dan una peculiaridad.

Siempre que un nuevo linaje interpretativo se impone, la tendencia de sus adherentes es estirar la cuerda del modelo hasta su límite. La variante del imperio polisinodial de Hespanha podría ser el imperio conectado de Subrahmannyam, configurador de una casi polaridad políticoadministrativa entre el imperio y sus partes ${ }^{14}$. 
Partes que ejercerían entre sí, replicando el mecanismo general del Imperio, la dinámica centroperiferia, desdoblándose el movimiento hacia la relación entre los centros coloniales y sus periferias, habiendo, por tanto, un core colonial con sus satélites intracoloniales, conformando una especie de ultraperiferia, a ejemplo de los sertões siempre asociados al desorden y la barbarie, espacios considerados fuera del Imperio. Constelación sui generis que, según Russel-Wood, era el fruto de la ineficiencia del gobierno metropolitano para imponer a la periferia la obligación de sustentar el centro, premisa básica del mercantilismo, resultando en la creación de oportunidades para que los colonos subvirtieran el sistema a través de lo que llama "cultura de evasión"15. La tendencia a sobrevalorar el nivel de poder incrustado en la escala local llega al extremo de transformar ese margen mínimo de mando en una variedad de autogobierno volcado para los intereses del bien común, asumida como verdaderos enclaves republicanos en el seno del Imperio, mimetizando a Jack P. Greene en el énfasis conferido al estilo europeo de gobernar aplicado a la manera local de hacer política del Nuevo Mundo, una incorporación reciente en los proyectos de investigación de Annick Lempérière para México ${ }^{16}$.

La revisión historiográfica de las teorías sobre una monarquía "descabezada" de Hespanha está en curso. Francisco Bethencourt y Diogo Ramada Curto discrepan del núcleo duro de esta concepción, relativa a la aludida flaqueza y "descabezamiento" del Imperio, concepción excesivamente empirista y carente de teorización. Laura de Mello e Souza rechaza la hipótesis de que su modelo, calcado del ordenamiento jurídico europeo, se ajustara al mundo de las colonias ${ }^{17}$. Para Pedro Puntoni, en el siglo XVII, el gobierno produce un poder concentrado en una técnica de dominación, destacando que:

[...] el análisis de las estructuras políticas y del arte de gobernar de los estados ibéricos, en su particular desarrollo en las colonias americanas, nos permite comprenderlas como una experiencia anticipatoria de una soberanía centrada en la dominación. Dominación definida en la relación de hostilidad permanente entre el príncipe y su pueblo, en este caso, los pueblos colonizados. Estos considerados no como un rebaño que apacentar o una familia que conducir, sino como una permanente amenaza: un enemigo que conquistar.

Así, siguiendo la formulación de Puntoni:

Es necesario rechazar una historiografía que sustenta una imagen de la política desde dentro del aparato de poder (procurando, sobre todo, valorar los procesos de construcción de consensos o de la cooptación y formación de las elites burocráticas o militares), obcecada por la "negociación entre partes" que entiende de naturaleza distinta (súbditos y monarcas) pero que se conforman, a la hora de la verdad, en el interior mismo del sistema político. Concejales, capitanes, proveedores, contratadores de diezmos, oficiales de diligencia, alcaides, soldados, tambores, gobernadores, consejeros del rey... e incluso el propio monarca, de alguna mane$\mathrm{ra}$, todos se configuran como piezas de un mecanismo político y burocrático cuyos fines se determinan en el juego político de los proyectos en conflicto, pero orientados por la dominación creciente del mercado. No se puede perder de perspectiva que la dominación no se impone, por fin, sobre el súbdito, que es también el agente de la colonización, sino sobre las poblaciones indígenas, africanas y europeas (desposeídas, sea de activos o de lugar social -en el caso de la sociedad de naturaleza estamental) que se someten a un sistema violento y deletéreo de dominación y explotación económica. En una situación de efectiva guerra viva contra estas poblaciones se construyen estas diversas alternativas de soberanía política en América, teniendo como norte fundamental la realización de los intereses del capital comercial ${ }^{18}$.

El ejercicio de la soberanía en la América portuguesa se expresaba bajo formas variadas. Son formas plurales del ejercicio del poder en la esfera colonial, en razón de la dispersión espacial de las poblaciones indígenas y de las situaciones de permanente enfrentamiento en las fronteras, que no dispensan, antes al contrario, exigían el polo integrador del Estado en proceso de formación y consolidación. 


\section{Imperios mercantiles: Jonathan Israel}

En esta parte, el punto de apoyo de nuestro objeto de estudio se desplaza de la problemática central que nos mueve, esto es, la relación entre el centro y la periferia, entre el core del sistema político y sus partes, al enfoque de la intensidad relacional entre las múltiples esferas del poder, evaluando si el poder decisorio emana del centro, si es compartido entre las esferas $y$, en este caso, cuál es la escala dimensional de los poderes decisorios ejercidos, para enfatizar el modo empírico de su operatividad material, propiamente económica, o el espacio físico, propiamente geográfico, de su incidencia concreta.

Jonathan Israel no caracteriza el espacio mercantil controlado por los holandeses a partir de las relaciones de dominación, subordinación o interacción entre la metrópoli y sus colonias. Mucho menos se plantea la cuestión del mando centralizado o descentralizado en las relaciones centro-periferia. Mira el Imperio en su dinámica mercantil, enfatizando las condiciones operacionales, los terms of trade ${ }^{19}$.

Analiza la primacía holandesa a la vista del comercio de grandes volúmenes de mercancías, el bulk carrying, historiando sus inicios en el comercio báltico, basado en el transporte de trigo, madera, sal y pescado, prácticas lucrativas que condujeron, al final del siglo XVI, a la extensión de su red comercial a los lugares más deseados del planeta, marcando posiciones en Oriente, en España y en las Indias Orientales. El salto decisivo en la construcción de este imperio vendría en los años 1590, con la ampliación de dominio colonial holandés por la vía de la penetración en los mercados de América, África y Asia, exactamente en el momento en que la República Holandesa se enfrentaba al Imperio español, de lo que se aprovecha para penetrar también en el comercio europeo, superando las barreras hasta entonces inexistentes. En este contexto, destaca el papel desempeñado por la creación de las compañías privilegiadas en 1602 y 1621, año simbólico de la constitución del Imperio mercantil holandés. En función del conflicto con España, los holandeses fueron impelidos a promover la intensificación del comercio interasiático por haber sido alejados del comercio de plata por los españoles, especializándose en un comercio al por mayor cuyo secreto era la búsqueda de la maximización de beneficios por vía de ganancias en fletes, seguros, almacenamiento $y$, sobre todo, diferencias de precios entre mercados a escala mundial, ejerciendo en esencia la más pura práctica del capital mercantil, que es la intensificación del lucro por la agilización de la circulación del capital ${ }^{20}$.

En suma, antes que enfocar la naturaleza de las relaciones entre la metrópoli holandesa y sus colonias, su forma centralizada o descentralizada de gestión del Imperio, problemática que mueve el interés de la mayoría de los historiadores especializados en la temática, Jonathan Israel refiere la naturaleza republicana del Estado holandés y la creación de un imperio colonial. En este sentido, apunta a una perspectiva de análisis original, la de la importancia de considerar la relevancia de los regímenes políticos de los Estados imperiales, en relación con la naturaleza de la dominación ejercida.

En términos estrictamente económicos, inspirados por Israel, más que reflexionar sobre el peso relativo de las tomas de decisión en el ámbito del Imperio portugués, tal vez fuera más productivo pensar en el papel de la acumulación mercantil, donde resaltaba el papel mayorista de la metrópoli portuguesa, cuya política de exclusividad comercial le permitía monopolizar el tráfico en la interconexión entre las diferentes partes, ejecutándolo directamente por medio de su marina mercante o pasándolo a otros cuando le convenía, pero reteniendo siempre las líneas de comercio transoceánico de más alta rentabilidad. De hecho, los portugueses vivían del transporte de las producciones realizadas en espacios de colonización directa o no, controlados por ellos; producciones asiáticas, productos brasileños o mano de obra esclava africana. Las producciones locales eran escasas, y en su gran mayoría se destinaban al autoconsumo ${ }^{21}$.

Por esta vía de comparación, el Imperio portugués tendría mayor similitud con el Imperio holandés, alejándose de la experiencia inglesa o española, aunque haya muy profundas diferencias en el régimen político de cada Estado, monárquico en Portugal, republicano en Holanda. 


\section{El Imperio portugués frente la moderna teoría de los imperios}

En sus variadas acepciones, imperios negociados, compuestos, conectados, sinodiales, resultan de experiencias históricas foráneas o de mimetizaciones historiográficas. ¿Si son válidas para el Imperio británico o el Imperio español, no lo serían también para el Imperio portugués? Para que la contraargumentación no parezca un esfuerzo estéril de la "historiografía nacionalista" en sus estertores, dejemos hablar, a propósito de la especificidad del Imperio portugués, a uno de los maestros de la deconstrucción de los imperios autoritarios, Jack P. Greene. Para él, mientras la monarquía española en el transcurso de los siglos XV y XVI consistía en una gran variedad de reinos y provincias, políticamente distintos por conservar los privilegios locales, Portugal era un reino unificado. Entre fines del siglo $X V$ e inicios del siglo XVI, los reyes D. João II y D. Manuel I hicieron notables esfuerzos para agrandar el poder del Estado a expensas de la nobleza y de las comunas, de cuyos lazos se volvieron menos dependientes en el caso de los recursos provenientes de la expansión marítima, que les permitió eximirse de la dependencia inherente a la estructura orgánica de su poder. Los recursos generados por su expansión marítima facilitaron aún más a los monarcas la eficiente cooptación de la nobleza, la compra de su lealtad, por su incorporación a los lucros del Imperio. Estos mecanismos "posibilitaron a la Corona alcanzar un grado de consolidación que, comparado con otros monarcas europeos, era asombroso"22.

Así como España, "Inglaterra incluía una amplia diversidad étnica, lingüística y cultural. Como Portugal, sin embargo, construyó muy temprano una estructura central duradera, incluyendo el tesoro real y un sistema nacional de Corte", que en el siglo XVI estaba "altamente integrado" ${ }^{23}$. En el siglo XVII, la reducción del beneficio comercial provocó el retroceso del poder monárquico portugués por la incapacidad de hacer frente a los costos crecientes de la burocracia y otros gastos estatales. En consecuencia, favoreció la recuperación de parte del poder perdido por las comunas y por la nobleza, sobre todo la última, beneficiada por su participación en las actividades comerciales, facilitada por el propio Estado, cuyo resultado final fue la recuperación de antiguos derechos y una considerable ampliación del mando sobre sus dominios específicos.
Mientras los recursos desperdigados por la expansión marítima viabilizaron la centralización de la monarquía portuguesa en el siglo XVI, reforzando su autoridad interna y externa, territorial y colonial, la crisis general del siglo $\mathrm{XVII}$ contribuyó a un retroceso significativo en las dimensiones de su poder. Los caudalosos recursos provenientes de la extracción aurífera brasileña en el siglo XVIII tendrían, necesariamente, que reforzar la tendencia a la retomada del mando político por el poder central, que se concretó, por ejemplo, en la apertura de la fiscalidad en las áreas mineras.

Si ese era el grado de centralidad vivida por la monarquía portuguesa, su capacidad de ejercer el poder de mando en el ámbito del Imperio era considerablemente mayor que la de España, debido a las formas de poder local realmente existentes, siendo entendidas como formas apropiadas de ejercicio de aquel poder. Expresiones de centralidad y no de "descabezamiento" del imperio.

\section{Modalidades imperiales y las dimensiones económico- religiosas del Imperio Portugués}

De forma más teórica, se podría decir que la categoría imperio tiene plena utilidad para el tratamiento de las dimensiones religiosas $y$ culturales, por su versatilidad y universalidad. Se demuestra fundamental para el tratamiento de las dimensiones político-administrativas, pues envuelve la necesaria estructura del imperio portugués en su especificidad histórica. Pero ve su capacidad explicativa reducida cuando nos remitimos a la dimensión económica, pues ocuparía indebidamente el lugar del concepto esencial que es, a nuestro modo de ver, el concepto de capitalismo en su fase de formación.

La noción de imperio, como hemos visto, es una categoría en expansión, que subsume el lugar ocupado otrora por conceptos más densos. Fenómeno semejante al concepto de imperialismo en la contemporaneidad, desplazado por el concepto más elástico de globalización. En la modernidad el concepto de imperio tomó el lugar del concepto de colonia y, por consiguiente, del 
propio sistema colonial. Por esta razón, las redes mercantiles ocuparon el lugar de las relaciones estructurales, proceso en el cual las redes fueron identificadas con las ligazones del imperio, sus conexiones vitales, en sustitución del mundo del trabajo, de las relaciones de producción. A todas luces, las redes mercantiles no pueden constituir, por sí mismas, el núcleo duro del sistema económico en su totalidad, esto es, en su más plena historicidad. Al surgir como esencia del sistema, expresan la autonomización de las formas frente a los contenidos, exactamente como la red de tráfico se sobrepuso a la esclavitud en la médula del sistema. Es la representación subsumiendo lo representado. Es, en suma, poner el tráfico y los traficantes en el lugar de la producción de la fuerza de trabajo y de las mercancías, de su distribución y redistribución, en fin, de la reproducción ampliada del sistema que se formaliza en la tripolaridad del Imperio portugués ${ }^{24}$.

En suma, la categoría imperio, o más propiamente la expresión imperio, no posee un estatuto de sustentación analítica, quedándole la condición de vocablo descriptivo, presente en la extrema variedad de sus acepciones, cuyo efecto nefasto es el de arremeter contra todo lo que se había construido en los espacios de la historia, pero dejando poco en su lugar. El concepto de capitalismo, a su vez, remite al referencial más amplio de la modernidad, pues los grandes teóricos pensaron la modernidad en gran medida como modernidad capitalista, inserta en el movimiento de laicización, de racionalización, de desacralización del mundo, que abrió camino al reinado absoluto de la mercancía.

Racionalidad que no falta, incluso, en la dimensión política, considerando la arquitectura original que los Estados imperiales ibéricos adoptarán en América, por su capacidad para amoldarse a situaciones históricas específicas en Europa y en el Nuevo Mundo, su capacidad para mantener estructuras sólidas en la transición del medievo a la modernidad, su habilidad para preservar las autonomías locales y como contrapartida hacer todos los esfuerzos para reforzar la centralidad política en el mundo colonial.

En este sentido, el artículo de Fernando Ciaramitaro sobre los virreinatos de Nueva España y Sicilia es extremadamente oportuno ya que ofrece nuevos elementos a las reflexiones arriba descritas. La cuidadosa comparación entre los distantes virreinatos de Sicilia y Nueva España le permite acercar conclusiones innovadoras en ese sentido, ya que pone en evidencia que obligado por la necesidad de gobernar un vastísimo imperio, el conjunto de los estados hispánicos tuvo que desarrollar un "nuevo sistema de administración centralizado", que iba a exigir "innovaciones constitucionales". En ese sentido se puede afirmar que "los soberanos castellanos fueron 'absolutistas' en el sentido de que la última capacidad de decisión pertenecía al rey" y que el ejercicio del poder administrativo no se hacía únicamente a través de los consejos, ni a través de sus secretarios, sino también a través de "otros organismos independientes" los cuales cedían una amplia capacidad de acción a sus representantes ya que era la única forma posible de hacer frente a las contingencias en un imperio tan vasto. Es por esta razón que de este lado del Atlántico "nunca se impuso un gobierno estrictamente absolutista fundamentado en la obediencia incondicional a las instrucciones de la metrópoli". Las organizaciones políticas locales, dada la inexistencia de definición de sus límites de acción, establecían una competencia sistemática entre sí y con las representaciones del poder central en "una constante contienda entre las fuerzas políticas", que terminaría por coartar sus posibilidades autonomistas ${ }^{25}$.

La conclusión de Fernando no deja margen para ningún tipo de duda. Según él:

Por primera vez desde el Imperio romano se intentó edificar una compleja organización, con su polifacética administración, a partir de un conspicuo número de Estados, total o parcialmente independientes. El grado de éxito logrado a lo largo de los siglos distingue a la Monarquía española de sus precedentes medievales: ésa fue la contribución más original del Imperio hispánico al desarrollo político del mundo moderno ${ }^{26}$.

Es decir, que se ejercía una centralidad posible en las condiciones americanas y no una descentralización impuesta por los organismos locales, como muchas de las teorías interpretativas sobre los Imperios ibéricos en América han dejado entrever, más aun, la autonomía reconocida es legitimada por el poder central. Una fórmula de gestión creativa que puede ser sintetizada en la expresión centralidad descentralizada, y que tuvo en la durabilidad secular el testimonio más efectivo de su eficacia; ni el 
estricto absolutismo practicado por las monarquías europeas ni el autogobierno de los pueblos como las recientes interpretaciones tienden a enfatizar. Se trata de una creación singular, que transfiere de Europa para América un procedimiento político típico de los Estados absolutistas, no del tipo de mantener un equilibrio de fuerzas sociales sino más bien de aprovecharse del conflicto entre ellas ${ }^{27}$, como demuestra el análisis de la competencia entre los organismos que constituyen el imperio.

Esta singular expresión política que fue propiciada por la experiencia americana y su resultado más tangible fue ofrecer subsidios históricos concretos a la definición de la naturaleza intrínseca de estos Estados $y$, por ende, a la elaboración teórica del iberismo ${ }^{28}$, que busca la formulación de una teoría política del Estado moderno que desconfía de los parámetros eurocéntricos clásicos.

\section{NOTAS}

1 ARRUDA, José Jobson de Andrade. "O Império Tripolar Atlântico ao final do Antigo Regime. Repensando a relação colonial - história e historiografia". En: Colóquio Internacional Economia e Colonização na Dimensão do Império Português: Historiografia e Perspectivas de Pesquisa, promovido por el Núcleo Dinâmicas Econômicas e Sociais, del Proyecto Temático Dimensões do Império Português. São Paulo: Cátedra Jaime Cortesão, FFLCH/USP. 30 de septiembre - 3 de octubre de 2008

2 Cf. GREENE, Jack. Peripheries and Center: constitutional development in the extended polities of the British Empire and the United States, 1607-1788. Athens: University of Georgia Press, 1986.

${ }^{3}$ Cf. SHILS, Edward. "Center and Periphery". En: The logic of personal knowledge: essays in honour of Michael Polanyi. Glencoe: The Free Press, 1961. p. 117-130. Edición en portugués: Centro e Periferia. Lisboa: Difel, 1992.

${ }^{4}$ Cf. GREENE, Jack P. Negotiated authorities. Essays in colonial, political and constitutional history. Charlottesville; London: University of Virginia, 1994, p. 4.

${ }^{5}$ Cf. BUSHNELL, Turner; GREENE, Jack P. “Peripheries, centers and the construction of early modern American Empires". En: DANIELS, Christie; KENNEDY, Michael V. Negotiated Empires: centers and peripheries in the Americas, 1500-1820. New York; London: Routledge, 2002, p. 11.

${ }^{6}$ Cf. GREENGRASS, Mark (org.). Conquest and Coalescence: the shaping of the state in the early modern Europe. London: Edward Arnold, 1991.

${ }^{7}$ Idem, p. 1-3. Cf. GREENE, Jack P. "Transatlantic colonization and redefinition of empire in the early modern era". En:
DANIELS, Christie; KENNEDY, Michael V. Negotiated Empires, op. cit., p. 278.

${ }^{8}$ Cf. Imperios del mundo Atlántico. España y Gran Bretaña en América (1492-1830). Madrid: Taurus, 2006.

${ }^{9}$ Cf. ELLIOTT, John. "A Europe of composite monarchies". Past and Present, 1992, n. 137, p. 48-71.

${ }^{10}$ Idem, p. 52-69.

${ }^{11}$ Cf. GRAFE, Regina; IRIGOIN, María Alejandra. "The Spanish Empire and its legacy: fiscal redistribution and political conflict in colonial and post-colonial Spanish America". Journal of Global History, 2006, v. 1, n. 2, p. 241-267.

${ }^{12}$ Cf. HESPANHA, António Manuel. Às vésperas do Leviathan. Coimbra: Livraria Almedina, 1994.

${ }^{13}$ Cf. "As estruturas políticas em Portugal na época moderna". En: TENGARRINHA, José (org.). História de Portugal. Bauru: EDUSC, 2001. p. 117-182.

${ }^{14}$ Cf. SUBRAHMANNYAM, Sanjay. "Connected histories: notes toward a reconfiguration or early modern history". Modern Asian Studies, v. 31, n. 3, 1997, p. 735-762.

${ }^{15}$ RUSSEL-WOOD, Anthony J. R. "Centers and peripheries in the luso-brazilian world, 1500-1808". En: DANIELS, Christie; KENNEDY, Michael V. Negotiated Empires, op. cit., p. 105-142. ${ }^{16}$ Cf. LEMPÉRIĖRE, Annick. Entre Dieu e le Roi, La Republique. México, XVle-XIXe siècles. Paris: Les Belles Letres, 2004.

17 SOUZA, Laura de Mello e. O sol e a sombra: política e administração na América portuguesa do século XVIII. São Paulo: Companhia das Letras, 2006.

18 PUNTONI, Pedro. "O Estado do Brasil: estruturas políticas e colonização". En: $2^{\circ}$ Ciclo de Conferências: O Atlântico IberoAmericano (séculos XVI-XVIII). Perspectivas Historiográficas Recentes, promovido por el Centro de História do Além Mar. Lisboa: Universidade Nova de Lisboa, 6 de novembro de 2007.

${ }^{19}$ Cf. ISRAEL, Jonathan. The Dutch Republic: Its rise, greatness, and fall. London: Oxford University Press, 1998.

${ }^{20}$ ARRUDA, José Jobson de Andrade. "Exploração Colonial e Capital Mercantil". En: SZMRECSÁNYI, Tamás (org.). História Econômica do Período Colonial. São Paulo: Hucitec; ABPHE 1996, p. 217-225

21 Cf. SILVA, José Gentil. "L'autoconsommation au Portugal (XIVe-XXe siécles)". Annales. Economies, sociétés, civilization, mars-avr. 1979, v. XXIV, n. 2, p. 250-288.

${ }^{22}$ Cf. BUSHNELL, Turner; GREENE, Jack P. "Peripheries, centers and the construction of early modern American Empires". En: DANIELS, Christie; KENNEDY, Michael V. Negotiated Empires, op. cit., p. 9

${ }^{23}$ Idem, ibidem, p. 9.

${ }^{24}$ Cf. ARRUDA, José Jobson de Andrade. "O império tripolar: Portugal, Angola, Brasil". En: SCHWARTZ, Stuart; MYRUP, Erik Lars. (org.). O Brasil no Império marítimo português. Bauru: 
EDUSC, 2008. p. 509-532.

${ }^{25}$ CIARAMITARO, Fernando. "El Virrey y su gobierno en Nueva España y Sicilia. Analogías y diferencias entre periferias de Imperio Hispánico". Estudios de Historia Novohispana, juliodiciembre de 2008, vol. 39, p.153.

${ }^{26}$ Idem, ibidem, p. 154

${ }^{27}$ ARRUDA, José Jobson de Andrade. A Grande Revolução Inglesa 1640-1780. São Paulo: Editora Hucitec, 1996, p. 68. 28 VIANNA, Luiz J. W. A Revolução Passiva: iberismo e americanismo no Brasil. Rio de Janeiro: Revan, 1997.

\section{REFERENCIAS BIBLIOGRÁFICAS}

ARRUDA, José Jobson de Andrade. "Exploração Colonial e Capital Mercantil". En: SZMRECSÁNYI, Tamás (org.). História Econômica do Período Colonial. São Paulo: Hucitec; ABPHE, 1996, p. 217-225.

. A Grande Revolução Inglesa 1640-1780. São Paulo: Hucitec, 1996.

"Cultura histórica: territórios e temporalidades historiográficas". Saeculum, Revista de História, jan./jun 2007, n. 16, p. 25-32.

"O Império Tripolar Atlântico ao final do Antigo Regime. Repensando a relação colonial - história e historiografia". En: Colóquio Internacional Economia e Colonização na Dimensão do Império Português: Historiografia e Perspectivas de Pesquisa, promovido por el Núcleo Dinâmicas Econômicas e Sociais, del Proyecto Temático Dimensões do Império Português. São Paulo: Cátedra Jaime Cortesão, FFLCH/USP. 30 de septiembre - 3 de octubre de 2008

"O império tripolar: Portugal, Angola, Brasil". En: SCHWARTZ, Stuart; MYRUP, Erik Lars. (org.). O Brasil no Império marítimo português. Bauru: EDUSC, 2008, p. 509-532. BUSHNELL, Turner; GREENE, Jack P. "Peripheries, centers and the construction of early modern American Empires". En: DANIELS, Christie; KENNEDY, Michael V. Negotiated Empires: centers and peripheries in the America, 1500-1820. New York; London: Routledge, 2002, p. 1-14.

CIARAMITARO, Fernando. "El Virrey y su gobierno en Nueva España y Sicilia. Analogías y diferencias entre periferias del Imperio Hispánico". Estudios de Historia Novohispana, juliodiciembre de 2008, vol. 39, p. 117-154.

ELLIOTT, John. "A Europe of composite monarchies". Past and Present, 1992, n. 137, p. 48-71.

. Imperios del mundo Atlántico. España y Gran Bretaña en América (1492-1830). Madrid: Taurus, 2006.

GRAFE, Regina; IRIGOIN, Maria Alejandra. "The Spanish Empire and its legacy: fiscal redistribution and political conflict in colonial and post-colonial Spanish America".
Journal of Global History, 2006, v. 1, n. 2, p. 241-267.

GREENE, Jack P. Peripheries and Center: constitutional development in the extended polities of the British Empire and the United States, 1607-1788. Athens: University of Georgia Press, 1986.

. Negotiated authorities. Essays in colonial political and constitutional history. Charlottesville; London: University of Virginia, 1994.

."Transatlantic colonization and redefinition of empire in the early modern era". En: DANIELS, Christie; KENNEDY, Michael V. Negotiated Empires: centers and peripheries in the America, 1500-1820. New York; London: Routledge, 2002, p. 267-282.

GREENGRASS, Mark (org.). Conquest and Coalescence: the shaping of the state in the early modern Europe. London: Edward Arnold, 1991.

ISRAEL, Jonathan. The Dutch Republic: its rise, greatness, and fall. London: Oxford University Press, 1998.

HESPANHA, António M.. Às vésperas do Leviathan. Coimbra: Livraria Almedina, 1994.

"As estruturas políticas em Portugal na época moderna". En:TENGARRINHA, José (org.). História de Portugal. Bauru: EDUSC, 2001. p. 117-182

LEMPÉRIÈRE, Annick. Entre Dieu e le Roi, La Republique. México, XVle-XIXe siècles. Paris: Les Belles Letres, 2004.

PUNTONI, Pedro. "O Estado do Brasil: estruturas políticas e colonização". En: $2^{\circ}$ Ciclo de Conferências: O Atlântico IberoAmericano (séculos XVI-XVIII) Perspectivas Historiográficas Recentes, promovido por el Centro de História do Além Mar. Lisboa: Universidade Nova de Lisboa, 6 de noviembre de 2007.

RUSSEL-WOOD, Anthony J. R. "Centers and peripheries in the luso-brazilian world, 1500-1808". En: DANIELS, Christie; KENNEDY, Michael V. Negotiated Empires: centers and peripheries in the America, 1500-1820. New York; London: Routledge, 2002, p. 105-142.

SHILS, Edward. "Center and Periphery". En: The logic of personal knowledge: essays in honour of Michael Polanyi. Glencoe: The Free Press, 1961, p. 117-130.

SILVA, José Gentil. "L'autoconsommation au Portugal (XIVe$\mathrm{XXe}$ siécles)". Annales. Economies, sociétés, civilization, marsavr. 1979 , v. XXIV, n. 2, p. 250-288.

SOUZA, Laura de Mello e. O sol e a sombra: política e administração na América portuguesa do século XVIII. São Paulo: Companhia das Letras, 2006.

SUBRAHMANNYAM, Sanjay. "Connected histories: notes toward a reconfiguration or early modern history". Modern Asian Studies, 1997, v. 31, n. 3, p. 735-762.

VIANNA, Luiz J. W. A Revolução Passiva: iberismo e americanismo no Brasil. Rio de Janeiro: Revan, 1997. 